\title{
0 Brasil e a construção de uma ideologia sustentável
}

Francisco Laurimar do Nascimento Andrade ${ }^{1}$

\section{Resenha do livro:}

DRUMMOND, José Augusto. Proteção e produção: biodiversidade e agricultura no Brasil. Rio de Janeiro: Garamond, 2014. $1^{\mathrm{a}}$ ed. $144 \mathrm{p}$

José Augusto Drummond nasceu em New York City (EUA), em 1948. É filho de pais brasileiros e cariocas e tem cidadania norte-americana e brasileira. Graduou-se em Ciências Sociais pela Universidade Federal Fluminense (Niterói), em 1975. Fez seus estudos de pós-graduação nos EUA (Mestrado em Environmental Science, pela The Evergreen State College, Olympia, Washington (EUA), concluído em 1988; Doutorado em Land Resources, pela University of Wisconsin, Madison (EUA), concluído em 1999). Desde 2004 é professor da Universidade de Brasília, lotado no Centro de Desenvolvimento Sustentável, no qual é docente permanente do Programa de Pós-Graduação em Desenvolvimento Sustentável. É coeditor da revista científica Sustentabilidade em Debate. É autor ou coautor de mais de 60 artigos científicos; autor, coautor, organizador ou coorganizador de 21 livros; autor ou coautor de 29 capítulos de livros.

O livro aqui resenhado é composto por dois capítulos que trazem à tona uma resposta crítica e minuciosa ao relatório de Miranda et al. (2008), membros de uma das unidades da Embrapa chamada "Embrapa Monitoramento por satélite”. A obra é uma edição própria e autêntica, publicada pela primeira vez

1 Universidade Federal Rural da Amazônia (UFRA) - Capanema - Brasil - laurimarangel@hotmail.com 
como livro de cunho crítico. Para tornar o texto apto a uma publicação na forma de livro, o autor incorporou novos dados a cada um dos capítulos para enriquecer a discussão. Drummond coletou vários dados em sites de órgãos governamentais e sites independentes, além de pesquisas feitas por ele próprio ao longo do desenvolvimento do livro. Também inúmeras sugestões de pesquisadores foram acrescentadas à discussão, sem falar nas leituras críticas em diversas versões feitas por colegas de Drummond. Outros textos de apoio foram usados para incorporar uma discussão mais firme à versão final do livro.

A priori, Drummond não tinha a intenção de publicar um livro de caráter crítico-explicativo. No entanto, os seus textos ganharam uma abrangência inimaginável e notória no decorrer das revisões. No início, Drummond escreveu o primeiro texto chamado "Áreas protegidas versus áreas ocupadas por atividades produtivas e infraestrutura no Brasil - há espaço para todos?” para ser uma pequena "resenha crítica" ao relatório de Miranda e colaboradores, porém, o texto incorporou dados importantes que o próprio autor levantou. O segundo texto , chamado "A biodiversidade como patrimônio - uma discussão social e cultural" surgiu como apoio a uma disciplina ministrada pelo autor. Nesse impasse de utilidades, Drummond decidiu publicar os dois textos como capítulos independentes de um mesmo livro.

O livro de Drummond é provocativo. A discussão é bem orquestrada na defesa de que sempre houve e sempre haverá espaço geográfico suficiente para abrigar diversas áreas, sejam elas protegidas ou produtivas. Apontando as falhas do relatório dos pesquisadores da Embrapa, o autor conseguiu criticá-los de várias formas, principalmente por meio da defesa da ideia de que as áreas protegidas não são exclusivamente para proteção da biodiversidade natural. Essas áreas são passíveis também de atividades agrícolas e, por vezes, de atividades de mineração, em pequena escala, além do extrativismo e da criação de pequenos animais.

No primeiro capítulo, a intenção de Drummond é mostrar que o Brasil tem extensão territorial suficiente para abranger tanto atividades agropecuárias como outros usos da terra, inclusive a proteção da biodiversidade natural. As observações do autor são fascinantes do ponto de vista territorial e ambiental do Brasil, pois mostram todo um contingente de atividades produtivas que conseguem crescer mesmo em extensas áreas com biodiversidade "natural". Ao contrário do que afirmam Miranda et al. (2008), Drummond consegue mostrar que as áreas ocupadas pela biodiversidade não impedem o crescimento das atividades produtivas agrícolas. Além disso, existem barreiras que realmente atrapalham o desenvolvimento agropecuário, como as instalações de infraestrutura, 
por exemplo, que abrangem extensas áreas e tornam o espaço que ocupam indisponíveis para a agricultura.

Apesar de controverso em vários aspectos, o relatório de Miranda e colaboradores, de acordo com Drummond, vem ganhando cada vez mais apoio desde que foi publicado, principalmente de pesquisadores que são contra as áreas protegidas. Entretanto, o apoio vai muito além do meio científico, pois também perpassa os meios político e econômico. A "bancada ruralista" presente no Congresso Nacional, por exemplo, já apresentou e debateu tal relatório, mostrando total apoio aos seus autores e à ideologia por eles apresentada. Nesse momento, Drummond é motivado a defender o seu ponto de vista, e, para isso, ele faz uma análise minuciosa sobre as atividades que podem ser desenvolvidas dentro de cada denominação das ditas áreas protegidas.

As UCs (Unidades de Conservação), por exemplo, são erroneamente generalizadas no relatório de Miranda e coautores, já que esses pesquisadores afirmam que as UCs, como um todo, impedem o desenvolvimento do setor agropecuário no Brasil, deixando de atentar para o fato de que existem basicamente 12 tipos de UCs, divididas em dois grupos - as de proteção integral e as de uso sustentável. As UCs de proteção integral realmente impedem o avanço agropecuário em áreas onde estão instaladas, mas a sua extensão territorial representa apenas um terço da área ocupada por UCs, sendo que os outros dois terços são representados por UCs de uso sustentável, nas quais é permitido o uso para atividades produtivas e de infraestrutura.

O autor também critica a mudança de leis já consagradas, como a recente aprovação da Lei n. 12.651, de 25 de maio de 2012, que revogou o Código Florestal, no qual a principal alteração foi a redução das áreas de proteção permanente e das reservas legais. Para Drummond, a preservação da natureza é um preço a ser pago por qualquer sociedade que queira se integrar à modernidade, haja vista que o uso sustentável dos recursos naturais é um tema cada vez mais presente no atual cenário de mudanças climáticas.

$\mathrm{O}$ autor admite que existem impedimentos ao desenvolvimento da agropecuária no Brasil, mas esse empecilho se encontra nas áreas abandonadas e subutilizadas e nas atividades industriais. Os argumentos de Miranda e colaboradores, por mais que pareçam "modernos", estão embasados em uma visão colonial e pós-colonial, na qual se pregava a expansão "horizontal" das áreas cultivadas, em oposição à expansão "vertical", pela qual se gera um aumento da produtividade e, consequentemente, agregação de valor.

Outro aspecto criticado no livro é o "acobertamento" do fato de que grandes áreas foram abandonadas após anos de usos inadequados pela agropecuária. É 
explícito que Miranda e colaboradores não se preocuparam em "amarrar" todos os pontos dos seus argumentos, pois deixaram de contabilizar, segundo Drummond, 200 milhões de hectares (23\% do território nacional) considerados pela Secretaria de Assuntos Estratégicos da Presidência da República como abandonados. Por outro lado, os autores da Embrapa dão grande destaque aos $23 \%$ do território brasileiro que estariam disponíveis para as atividades agropecuárias, considerado por eles um percentual extremamente baixo. Mas, rompendo com essa visão pessimista, Drummond mostra que os $23 \%$ subestimados é um contingente de terras significativo, considerando a extensa fronteira territorial do Brasil e a quase que total ausência de fatores ambientais adversos.

No segundo capítulo, o autor sustenta a hipótese de que a biodiversidade é constituída pelo processo histórico de evolução, sendo que as ações antrópicas, principalmente as de finalidades agropecuárias, não acrescentam em nada ao valor natural da biodiversidade, valor esse insubstituível e independente ao Homo sapiens. Além disso, a discussão sustenta que a biodiversidade natural não foi construída pelo homem e, tampouco, pode ser por ele renovada, devendo ser analisada como patrimônio "externo". Um termo bastante encontrado na discussão do segundo capítulo é agrobiodiversidade, ou seja, a diversidade de organismos vivos ou não que são manipulados pelo homem e, por vezes, considerados parte integrante da biodiversidade natural. Porém, o autor enfatiza que animais ou plantas domésticos não enriquecem em nada a biodiversidade, visto que ela é anterior aos homens e será também posterior a eles, o que obedece a uma lógica de independência construtiva, isto é, não necessita de ajuda humana para os seus processos evolutivos.

A obra de Drummond é, sem dúvidas, esclarecedora, tanto do ponto de vista territorial do Brasil quanto conjuntural, isso porque o autor lança mão de inúmeras leis e dados estatísticos para mostrar que Miranda e colaboradores estão equivocados. Além disso, percebe-se claramente que a biodiversidade brasileira é rica em recursos, podendo sim abranger atividades produtivas e de proteção. Para tanto, é necessário adequar as aspirações agropecuárias à sustentabilidade, pois os fenômenos naturais de construção dos ecossistemas não são inerentes ao homem e, por isso, não podem ser criados ou renovados. Dessa forma, uma vez manipulada, a diversidade natural dá origem à agrobiodiversidade, que, segundo Drummond, não contribui para o enriquecimento de espécies nativas.

O livro de Drummond, em sua forma mais abrangente, perpassa a simples crítica, chegando a ser uma obra social. Essa história, contada de forma inteira e sem omissões de dados, deve ajudar, principalmente, profissionais engajados 
na busca do verdadeiro desenvolvimento sustentável e jovens que buscam um maior conhecimento do potencial produtivo brasileiro.

\section{Referências}

DRUMMOND, José Augusto. Proteção e produção: biodiversidade e agricultura no Brasil. Rio de Janeiro: Garamond, 2014. $1^{\text {a }}$ ed. 144 p. ISBN 9788576173601.

MIRANDA, Evaristo Eduardo et al. Alcance Territorial da Legislação Ambiental e Indigenista. Campinas, Embrapa Monitoramento por Satélite, 2008. Disponível em: $<$ http://www.alcance.cnpm.embrapa.br/>. Acesso em: 20 nov. 2018.

Recebido em 23/08/2017

Aprovado em 07/11/2018

\section{Como citar esta resenha:}

ANDRADE, Francisco Laurimar do Nascimento. O Brasil e a construção de uma ideologia sustentável. Contemporânea - Revista de Sociologia da UFSCar, v. 8, n. 2, jul.- dez. 2018, pp. 673-677. 